\title{
Información para Toma de Decisiones en un ente Público de Financiamiento a la Pequeña Industria en Venezuela
}

\author{
Leal Morantes, Miraidy* \\ Gamboa Cáceres, Teresa \\ Briceño Quintero, María
}

\section{Resumen}

Este artículo presenta un estudio de caso de los informes generados en un organismo público de financiamiento, específicamente el Fondo Rotatorio para el Financiamiento y Desarrollo de la Ar. tesanía, Pequeña y Mediana industria del Estado Zulia (FONFIDEZ) en Venezuela. A partir de la reflexión teórica sobre las posibilidades y limitaciones de la información contable para la toma de decisiones, se analizan las necesidades de información de los diferentes niveles decisorios y los informes producidos por el sistema contable del Fondo, a fin de determinar su utilidad para satisfacer las necesidades gerenciales en función de la toma de decisiones. Los resultados evidencian que el sistema contable analizado presenta limitaciones para generar información gerencial pertinente, por cuanto: no es oportuna, los informes están sobrecargados, la información útil está y dispersa, los datos de diversas fuentes sobre el mismo asunto no coinciden. Se concluye que el sistema debe adaptarse a los requerimientos de información de un organismo para responder a las necesidades de financiamiento de las pequeñas y medianas industrias en función de potenciar el desarrollo económico en un entorno, globalizado e influenciado por los cambios en la tecnología de información; estos cambios suceden a gran velocidad e inciden en las organizaciones públicas y privadas, impulsando procesos como la reingeniería y la reestructuración, que reducen las oportunidades laborales para contadores.

Palabras clave: Organismos Públicos de Financiamiento, Informes Contables, Toma de Decisiones, Tecnología de Información, Reestructuración.

Recibido: 01-03-23 . Aceptado: 01-05-21

Las autoras son Contadores Públicos adscritas al Centro de Estudios de la Empresa, FCES, Universidad del Zulia, en el cual desarrollan el Programa "Estrategias de Modernización Empresarial". Autora para la correspondencia: Miraidy_Leal@latinmail.com. 


\section{Information for Decision Making in Public Financing of Small Industry in Venezuela}

\section{Abstract}

A study of cases is made based on reports generated by a public financing agency, specifically the Rotational Fund for the Financing and Development of Handicrafts, Small and Medium-sized Industry in Zulia State (FONFIDEZ) in Venezuela. Based on a theoretical reflection as to the possibilities and limitations of accounting information on which to base decision making, the need for information on different decisive levels, and the reports produced by the FONFIDEZ accounting system are analyzed for the purpose of determining their utility in satisfying management needs for decision making. The results show that the accounting system analyzed has limitations in reference to the generation of the necessary management information, since it is not opportune, the reports have too much information, the necessary information is present but dispersed, and the information from different sources as to the same phenomenon do not coincide. The conclusion is that the system should be adapted to the informational requirements of one organism in order to respond to the financial necessities of small and medium sized industry in order to empower economic development in an environment that has been globalized and that is influenced by changes in informational technology. These changes occur with great speed and influence public and private organizations, mobilizing processes such as re-engineering and re-structuring, which reduce labor opportunities for accountants.

Key words: Public financing organizations, accounting reports, decision-making, informational technology, re-structuring.

\section{Introducción}

Uno de los principales objetivos de la Contabilidad consiste en obtener y suministrar intormación sobre las operaciones económico-financieras realizadas por una institución pública o privada, de modo que sea útil para la toma de decisiones oportunas de los diferentes usuarios. Para que dichas decisiones sean lo más acertadas posible, es necesario que la información sea pertinente, clara y a tiempo,, de manera que las mismas se encuentren suficientemente soportadas $y$ se pueda actuar en el momento preciso.

Todo sistema contable, apoyándose en la contabilidad administrativa y la contabilidad financiera, debe ser capaz de recopilar y suministrar información a través de informes especificos, presentados de la forma más conveniente, suficiente y completa, de acuerdo al fin para el cual deben servir. En este sentido, la contabilidad administrativa tiene como propósito suministrar información en función de facilitar la planificación y el control de las operaciones, mientras que la contabilidad financiera suministra información a usuarios externos por medio de informes basados en principios de contabilidad generalmente aceptados.

Es evidente el papel primordial que desempeña la información en el mundo de hoy, en donde las organizaciones se desenvuelven en un medio cambiante, globalizado, caracterizado por cambios 
tecnológicos (especialmente en las áreas de computación y telecomunicaciones), transformaciones políticas, sociales, económicas que producen diversos impactos en la organización y sus estrategias gerenciales, conllevando incluso, a procesos de reestructuración y reingenieria, razón por la cual las organizaciones y las personas deben estar preparadas para responder a esos cambios de la mejor forma posible; no es suficiente estar informado en forma pasiva, hay que sacar provecho a la información para actuar proactivamente ante los cambios del entorno. En este aspecto, los profesionales de la Contaduría Pública deben ser capaces de diseñar sistemas contables que funcionen como verdaderos sistemas de información gerencial.

En la práctica, algunos informes generados por el sistema contable no satisfacen las necesidades de información para la toma de decisiones. A fin de verificar la validez de la práctica, en esta ocasión se realizó un estudio para analizar la utilidad de los informes producidos por el Fondo Rotatorio para el Financiamiento y Desarrollo de la Artesanía, Pequeña y Mediana Industria del Estado Zulia (FONFIDEZ).

El estudio abarca tres aspectos principales:

- Utilidad de la información suministrada por la contabilidad para la toma de decisiones.

- Informes generados en FONFIDEZ y su utilidad como herramienta para la toma de decisiones.

- Nuevas Tecnologías de Información, Reestructuración y Mercado Laboral para Contadores Públicos.

\section{La Contabilidad como base para la Toma de Decisiones}

\subsection{Naturaleza de la Contabilidad}

En el cambiante mundo de los negocios cada día se requiere información confiable sobre la situación financiera de las organizaciones. A través del tiempo los individuos $\mathrm{y}$, especialmente las empresas, han requerido registrar sistemáticamente las múltiples transacciones $y$ hechos económicos que se producen en las mismas, utilizando para ello la Contabilidad.

Al respecto Bernstein (1996: 35) señala que "la Contabilidad se ocupa de la expresión cuantitativa de fenómenos económicos. Como disciplina, surgió por la necesidad de contar con una estructura para el registro, la clasificación y la comunicación de datos económicos". Esta definición no se refiere exclusivamente a información monetaria. Sin embargo, de acuerdo con la práctica, pareciera que la Contabilidad debería limitarse a la presentación de información monetaria, con lo cual se le está dando mayor énfasis a la contabilidad financiera. No obstante, el sistema contable debe ser capaz de suministrar información que satisfaga también las necesidades de la contabilidad administrativa, principalmente porque este tipo de información es más pertinente para la gestión empresarial.

En efecto, Name (1980: 11-12) plantea que, "el contenido de la contabilidad... consiste en reflejar cualitativamente los fenómenos, hechos y relaciones que tienen lugar en el transcurso de los 
procesos económicos. Esta imagen o reflejo cualitativo sólo puede brindarse por medio de la observación, medición y registro de esos fenómenos, hechos y relaciones que conforman toda la actividad socioeconómica... la contabilidad no sólo constituye un reflejo cuantitativo de los fenómenos socioeconómicos, sino que esencialmente pone de relieve el aspecto cualitativo de cada sistema social".

Lo anterior pone de relieve que ninguna información es exclusivamente cuantitativa, puesto que toda medición expresa la cantidad de una cualidad determinada. Justamente, en el caso de la contabilidad la clasificación de los hechos económicos reflejada en el código de cuentas constituye el aspecto cualitativo que será cuantificado.

Tradicionalmente se ha dicho que la Contabilidad debe producir información indispensable, tanto para la gerencia, como para terceros interesados en el desarrollo de la misma. Sin embargo, en la práctica contable se ha dado mayor énfasis a la contabilidad financiera, dirigida casi exclusivamente a la preparación de informes para usuarios externos $y$, menos importancia a la preparación de informes para uso gerencial. No hay que olvidar que muchos profesionales pueden trabajar, $y$, en efecto trabajan, bajo relación de dependencia, en cuyo caso deben servir de apoyo a la gerencia. En este sentido, el Contador debe suministrar información para la toma de decisiones, por lo cual es necesario que conozca y comprenda cómo el producto de su labor puede ayudar a la alta dirección a desarrollar sus actividades.

\subsection{Utilidad de la Contabilidad}

El objetivo fundamental de la contabilidad consiste en obtener y suministrar información sobre las operaciones realizadas por una entidad pública o privada, de modo que sea útil para la toma de decisiones de los usuarios internos y externos de la misma. Su importancia radica principalmente en que el conocimiento y comprensión de los eventos y transacciones que afectan los recursos de la organización, facilita su dirección apropiada. En consecuencia, la Contabilidad debe presentar aquellos aspectos que expresen la situación y el desarrollo de la institución en diferentes informes, de la manera más adecuada y suficiente, de acuerdo a los fines para los que debe servir.

Un adecuado sistema contable debe ser capaz de suministrar información, tanto para uso interno como para uso externo. El tipo de información que contengan dichos informes dependerá de la naturaleza de la organización, las áreas críticas de éxito identificadas y las necesidades de información de los usuarios.

Según Khadem y Lorber (1995), la información suministrada por los informes gerenciales debe servir de soporte a la administración de la empresa (directores generales, directores funcionales, gerentes de área, jefes de departamentos) en su gestión diaria, así como para la planeación a largo plazo. Entre otros aspectos, deben informar sobre: Desempeño global de la empresa, desempeño del personal, calidad de los productos, participación en el mercado, eficacia de las operaciones, rentabilidad de productos o servicios, Productividad, y otros aspectos que requieran atención especial. 
La información para uso interno, debido a su naturaleza, es de un nivel de detalle mucho mayor que la suministrada a los usuarios externos. Por lo mismo, su presentación no está regida por leyes ni por otro tipo de disposiciones, sino exclusivamente por la necesidad de la información y la creatividad de quienes la preparan (Guajardo, 1995: 22). Por el contrario, los informes para uso externo (denominados estados financieros), están regidos por normas y son utilizados principalmente por accionistas, acreedores, sindicatos, Estado, instituciones financieras, clientes actuales y potenciales y público en general. Básicamente informan sobre:

- Situación fínanciera de la empresa a una fecha determinada.

- Resultado de las operaciones de la empresa en un período determinado.

- Cambios en la posición financiera en un período determinado.

A continuación se presenta un cuadro comparativo donde se resumen los principales tipos de usuarios de la información contable, asi como los informes utilizados y los propósitos de los mismos (Tabla 1).

En toda organización se produce el ciclo de entrada, procesamiento y salida de información dirigido a satistacer las necesidades de los diferentes usuarios; sin embargo, para que el sistema contable genere información pertinente es necesario asegurar la calidad del proceso en su totalidad. Tomando como base a Redondo (1992: 2), consideramos que para lograr este objetivo se debe:

- Registrar cronológicamente los hechos o transacciones de la empresa en base a sistemas y procedimientos técnicos.

- Clasificar las operaciones de acuerdo a su naturaleza.

- Resumir la información por grupos o categorías para un lapso dado.

- Interpretar dichos resúmenes con el fin de proporcionar intormación razonada.

El autor pasa por alto la identificación de las necesidades de información de los diferentes usuarios, asunto habitual en Contaduria, pues se asume que dichas necesidades son conocidas.

El resultado o salida de este proceso son los informes contables, los cuales se suponen insumos, de uso interno o externo, necesarios para la toma de decisiones. Sin embargo, estos informes con frecuencia no responden a las expectativas gerenciales y los datos contenidos en los mismos se interpretan por sí mismos sin referencia a las metas previstas, limitando su capacidad evaluativa, excepto en el caso del control presupuestario. No obstante, en el sector público el control presupuestario da cuenta si las partidas se invierten o gastan en aquello que estaba previsto, sin importar la validez y pertinencia de las estimaciones presupuestarias, ni el resultado concreto obtenido.

Al respecto Osbome y Gaebler (1994: 177-178), señalan que en los presupuestos del sector público el dinero se distribuye en ítems especificos, por lo cual en caso de producirse excedentes en algunos de ellos no es posible la transferencia de los recursos a otras partidas que los necesiten. Esto provoca despilfarro de recursos, ya que los administradores, para evitar recortes en las partidas 


\section{Tabia $N^{\circ} 1$}

\section{Informes contables por tipo de usuario}

\begin{tabular}{|c|c|c|c|}
\hline \multicolumn{2}{|c|}{ Tipo de Usuario } & Informe Utilizado & Propósito \\
\hline \multirow[t]{3}{*}{ Interno } & Alta Gerencia & $\begin{array}{l}\text { Estados } \\
\text { Financieros } \\
\text { Informes } \\
\text { generados por la } \\
\text { Contabilidad } \\
\text { Administrativa }\end{array}$ & $\begin{array}{l}\text { Planeación a largo plazo } \\
\text { Evaluar el desempeño global } \\
\text { de la organización }\end{array}$ \\
\hline & $\begin{array}{l}\text { Gerencia } \\
\text { Media }\end{array}$ & $\begin{array}{l}\text { Estados Financieros } \\
\text { Intormes generados } \\
\text { porla Contabilidad } \\
\text { Administrativa }\end{array}$ & $\begin{array}{l}\text { Planear y controlar las operaciones de la organi- } \\
\text { zación en el mediano plazo } \\
\text { Evaluar el desempeño de cada división o depen- } \\
\text { dencia } \\
\text { Tomar acciones preventivas y correctivas }\end{array}$ \\
\hline & $\begin{array}{l}\text { Gerencia } \\
\text { Operativa }\end{array}$ & $\begin{array}{l}\text { Estados Financieros } \\
\text { Informes generados } \\
\text { por la Contabilidad } \\
\text { Administrativa }\end{array}$ & $\begin{array}{l}\text { Planear, controlar y evaluar las operaciones dia- } \\
\text { rias de la organización }\end{array}$ \\
\hline \multirow[t]{4}{*}{ Externo } & Accionistas & $\begin{array}{l}\text { Estados } \\
\text { Financieros }\end{array}$ & $\begin{array}{l}\text { Tomar decisiones de inversión y crédito } \\
\text { Medir la capacidad de crecimiento, estabilidad y } \\
\text { redituabilidad de la empresa } \\
\text { Determinar la solvencia y liquidez de la empresa } \\
\text { y su capacidad para generar recursos } \\
\text { Evaluar el origen y las características de los re- } \\
\text { cursos financieros del negocio y el rendimiento } \\
\text { de los mismos } \\
\text { Evaluar la gestión de la Administración }\end{array}$ \\
\hline & Acreedores & $\begin{array}{l}\text { Estados } \\
\text { Financieros }\end{array}$ & Determinar capacidad de pago de obligaciones \\
\hline & $\begin{array}{l}\text { Trabajadores } \\
\text { (Sindicato) }\end{array}$ & $\begin{array}{l}\text { Estados } \\
\text { Financieros }\end{array}$ & $\begin{array}{l}\text { Determinar su participación en los beneficios de } \\
\text { la empresa }\end{array}$ \\
\hline & Fisco & $\begin{array}{l}\text { Declaraciones } \\
\text { de Renta }\end{array}$ & Determinar el importe de los impuestos \\
\hline
\end{tabular}

Fuente: Leal et al. (2001). Información para toma de decisiones en Organismos Públicos de Financiamiento.

para el próximo año, gastan todo el presupuesto asignado así no lo necesiten.

En el caso de los usuarios externos generalmente requieren informes para evaluar la situación financiera de la empresa, otorgar créditos, determinar las ganancias o pérdidas fiscales obtenidas en los ejercicios económicos, etc.; para los usuarios externos, los informes contables tradicionales (estados financieros) tienen mayor pertinencia.

Los usuarios internos, directores y gerentes, generalmente deben tomar decisiones de carácter operacional, finan- 
ciero o de inversión; por lo tanto, necesitan un sistema que recopile información clave, periódica, oportuna y pertinente para la consecución de sus objetivos. Sin embargo, la mayoría de las veces los informes generados por el sistema contable no satisfacen las necesidades gerenciales en función de la toma de decisiones, porque están más orientados al usuario externo.

El problema antes mencionado se origina fundamentalmente, según Khadem y Lorber (1995: 10, 17), por desconocimiento de la información requerida para la consecución de los objetivos, uso inadecuado de los canales de comunicación o inexistencia de una correcta integración entre el departamento de Contabilidad y las demás unidades organizativas. En consecuencia, en muchos casos se suministran informes extemporáneos, carentes de datos importantes o información excesiva, lo que obstaculiza el logro de las metas propuestas y la toma adecuada y oportuna de decisiones.

Al respecto, Cubillán (1998: 114) plantea que "la existencia de registros adecuados que generen informes pertinentes y oportunos constituye un apoyo vital, aunado a la capacidad del nivel gerencial para utilizarlos como base para la toma de decisiones". Es decir, la otra cara del problema está en el usuario de la información; con frecuencia para los gerentes (especialmente los del sector público elegidos con criterios politico-clientelares), los informes contables resultan poco comprensibles, lo cual contribuye a desvalorizar su uso potencial.

\subsection{Limitaciones de la Información Contable para la Toma de Decisiones y el Control}

Con base en las características de los Estados Financieros, establecemos las siguientes limitaciones en el uso de la información contable para la toma de decisiones:

- Sólo presenta información cuantificable en términos monetarios. Existen aspectos relevantes de la organización, de difícil valuación en unidades monetarias, que no se muestran en los Estados Financieros, tales como: experiencia, desempeño y motivación del personal; calidad y cobertura del senvicio; eficacia de las operaciones, entre otros. El Estado de Ganancias y Pérdidas refleja en sus resultados una medida de eficiencia absoluta, pero solo cuando se calcula la rentabilidad se obtiene la máxima medida de eficiencia global; sin embargo, esto no se presenta regularmente como parte de los Estados Financieros. Asimismo, el Estado de Ganancias y Pérdidas incluye los costos globales, pero la verdadera medida de eficiencia es el costo unitario, el cual tampoco forma parte de los Estados Financieros.

- Uso del criterio personal del contador para el registro y clasificación de las transacciones y eventos económicos. Como señala Berstein (1996: 31), "el uso del criterio personal en la preparación de estados financieros es inevitable. La limitación que de ello se deriva es la consiguiente variación en la calidad y fiabilidad de 
las presentaciones de estados financieros. Los estados financieros pueden no ser de calidad y fiabilidad uniformes como consecuencia de las diferencias de carácter y calidad de los criterios aplicados por los contables en su preparación".

- Presentan sólo información histórica, no se acostumbra a incluir comparaciones con las metas establecidas.

- Responden básicamente a los requisitos de usuarios externos. Aún cuando se habla de contabilidad administrativa y contabilidad financiera, la contabilidad es una sola, que debe estar diseñada para responder a las necesidades de la toma de decisiones.

\section{La Información en un Organismo Público de} Financiamiento a la Pequeña Industria

Debido a que el Sistema de Contabilidad de cualquier empresa pública o privada, juega un papel fundamental, por ser fuente proveedora de información, es importante estudiar la utilidad de los informes generados por dicho sistema. Por ello, se seleccionó un organismo público de financiamiento: el Fondo Rotatorio para el Financiamiento y Desarrollo de la Artesanía, Pequeña y Mediana Industria del Estado Zulia (FONFIDEZ), a fin de analizar la utilidad de los informes generados por su sistema contable para satisfacer las necesidades gerenciales en función de la toma de decisiones.

FONFIDEZ, fue creado por Ley regional en 1994, durante la gestión regio. nal del Movimiento al Socialismo, con Lolita Aniyar en la Gobernación, en un pe- riodo en que se intenta impulsar un proyecto con compromiso social. Sin embargo, sólo comienza sus operaciones en 1997, durante el gobierno encabezado por Arias Cárdenas, uno de los militares que dirigió el intento de golpe en 1992 junto con el actual Presidente de la República, al cual posteriormente enfrentó por la opción presidencial.

FONFIDEZ actúa como un ente autónomo, adscrito a la Secretaría de Desarrollo Social de la Gobernación del Estado Zulia, pero con personalidad jurídica y patrimonio propio. Hasta 1999 la estructura organizativa del Fondo era de tipo funcional, donde cada departamento o sección debía cumplir una función específica. Las principales áreas funcionales eran las siguientes: Promoción, Asistencia Técnica, Asistencia Financiera, Asistencia Jurídica, Administración.

El Fondo "tiene por objeto promover... el desarrollo de la Artesania y de la Pequeña y Mediana Industria del Estado Zulia,... (mediante asistencia) crediticia, técnica, organizativa, gerencial, de calidad y de capacitación y adiestramiento necesarios;... promocionará la realización de estudios en dichos sectores que permitan definir su propio papel de desarrollo socio-económico del Estado Zulia y del país en general" (ALEZ, 1994).

Los fines asignados legalmente al Fondo son suficientemente amplios como para acometer un trabajo integral de apoyo a la artesanía, pequeña y mediana industria. Sin embargo el Fondo ha centrado su atención en la actividad crediticia, dejando de lado los servicios que garantizan la supervivencia de las empresas financiadas y su aporte al desarrollo económico de la región. 
Además, el Fondo se basó en el concepto de artesanía contenido en la Ley, el cual restringe la actividad y por lo tanto la oportunidad del financiamiento, a la "producción de unidades singulares o piezas originales"; de esta forma la artesanía pierde su contenido popular y se reduce a una actividad relativamente elitesca, lo cual se evidencia en el tipo de artesanos que pudieron obtener financiamiento. Igualmente, aunque ha otorgado algunos créditos industriales, ha centrado la actividad en préstamos para la adquisición de taxis que ostentan propaganda institucional-partidista, desvirtuando el objeto central de atención.

Durante los pocos años de funcionamiento, el Fondo centró su atención en las actividades de financiamiento, descuidando los otros fines establecidos en la Ley de Creación, por lo cual se hizo necesaria su reestructuración, previa evaluación de la situación actual.

En Abril de 1999 es designado un nuevo presidente en el Fondo con lo que se inicia el proceso de evaluación y rediseño, basado en la Reingeniería de Procesos de Hammer y Champy (1996), propuesta que fue discutida por el Directorio en abril y aprobada en mayo de 1999. Lo que se buscaba era modificar la organización, para redefinir una nueva estructura administrativa basada en procesos, identificando los procesos básicos y de apoyo.

Bajo esta concepción, se definieron diez procesos básicos y cuatro procesos de apoyo (Gamboa et al, 1999). Tomando en consideración la naturaleza del Fondo y las responsabilidades que le asigna la Ley de Creación, fueron definidos los siguientes procesos básicos:
a)Definición de Políticas, Proyección Institucional y Posicionamiento Estratégico; b) Captación de Fondos; c) Administración de Recursos Financieros; d) Evaluación, Reformulación y/o Formulación de Proyectos; e) Revisión de Informes para el Directorio; f) Revisión y Aprobación de Créditos; g) Administración de Programas y Convenios; h) Apoyo Técnico Permanente a la PYMI; i) Administración y Recuperación de Créditos y i) Seguridad Jurídica.

Por otra parte, para facilitar el desarrollo de los procesos básicos y el funcionamiento general del Fondo, se establecieron los siguientes procesos de apoyo: a) Información: Diseño, Elaboración de Informes y Mantenimiento de la Base Datos; b)Administración de Personal; c) Desarrollo, Mantenimiento y Protección de Planta y Equipo; d) Compras.

Con el nuevo modelo organizativo, la institución adquiere una estructura plana, con sólo tres niveles jerárquicos: Presidencia, Gerencia General y Equipos de Trabajo, conformados por tres Equipos de Proyectos y un Equipo de Información y Base de Datos.

\subsection{Necesidades de Información de FONFIDEZ}

Para fundamentar la toma de decisiones, además de la información financiera convencional, FONFIDEZ requiere información de carácter no financiero pertinente y oportuna que garantice el óptimo funcionamiento de la institución.

Ambos tipos de información son importantes, como plantea Rodríguez (1999: 30) "las medidas no financieras 
tienen que usarse en forma mancomunada con las financieras en una combinación óptima en cada nivel de responsabilidad en aras del objetivo de la organización, ya que tienen efectos positivos en los resultados operativos y por ende en los financieros".

La Tabla N $N^{\circ} 2$ precisa las necesidades de información de cada nivel decisorio en FONFIDEZ.

Al analizar las necesidades de información de FONFIDEZ se evidencia que existe poca correspondencia con la información suministrada por los informes convencionales.

Para desarroilar adecuadamente sus procesos básicos y fundamentar la toma de decisiones, FONFIDEZ necesita información cuantitativa no monetaria que el sistema contable de la institución no estaba en capacidad de suministrar. Por ello, se requiere que la persona responsable de la información de carácter administrativo diseñe y prepare los informes necesarios para mantener informados a los diferentes niveles gerenciales sobre los resultados de la gestión.

\subsection{Informes Generados en FONFIDEZ}

Los principales informes generados hasta el momento de la reestructuración (mediados de 1999), son los siguientes: Balance General, Estado de Recursos y Egresos, Situación Bancaria, Situación de Cuentas por Cobrar, Presupuestos Anuales, Ejecución Presupuestaria.

Para caracterizar los informes y determinar su capacidad de satisfacer las necesidades gerenciales para la toma de decisiones, seleccionamos las siguientes variables: destinatarios, periodicidad, oportunidad y pertinencia.

En la Tabla $\mathrm{N}^{\circ} 3$ se muestran las principales características de los informes generados en el Fondo.

Con base en la información suministrada en la Tabla $\mathrm{N}^{\circ} 3$, es necesario destacar lo siguiente:

a. A excepción de la Contraloría General del Estado Zulia, los destinatarios de los informes son usuarios internos; sin embargo, los informes no satisfacen sus necesidades de información por lo siguiente:

- La mayoría de los informes se elaboran anualmente. La gerencia, para desarrollar su gestión, requiere información de períodos más cortos (diaria, semanal, quincenal).

- Como consecuencia de lo anterior, la información no llega a manos del usuario cuando la necesita.

- El tipo de información contenida en los informes responde básicamente a los requerimientos de los usuarios externos. Sólo algunos de los informes contienen cierta información relevante para determinar el comportamiento de la organización.

b. Para el momento de la reestructuración, una información tan importante, como lo es la situación crediticia de los convenios, no está disponible porque no ha habido un registro y seguimiento sistemático de los mismos. Igual sucede con los créditos ordinarios, lo cual ha producido retraso en las cobranzas e incluso (en algunos casos) el cliente no tiene certeza del monto que debe pagar. 
Tabla No. 2

Necesidades de información de los niveles decisorios de FONFIDEZ

\begin{tabular}{|c|c|c|}
\hline $\begin{array}{c}\text { Unidades } \\
\text { Organizacionales }\end{array}$ & Procesos & Necesidades de Información \\
\hline Directorio & $\begin{array}{l}\text { Definición de Políticas } \\
\text { Proyección Institucional } \\
\text { y Posicionamiento Estratégico } \\
\text { Revisión y Aprobación } \\
\text { De créditos }\end{array}$ & $\begin{array}{l}\text { Proyecto de presupuesto } \\
\text { Informes de evaluaciones de proyectos, } \\
\text { realizadas por los equipos correspondien- } \\
\text { tes y revisadas por la Gerencia General* } \\
\text { Convenios de cooperación* } \\
\text { Situación del FONDO: Estados financie- } \\
\text { ros, Indicadores financieros } \\
\text { Memoria y cuenta anual }\end{array}$ \\
\hline Presidencia & $\begin{array}{l}\text { Definición de Políticas } \\
\text { Proyección Institucional } \\
\text { y Posicionamiento Estratégico } \\
\text { Captación de Fondos } \\
\text { Administración de Recursos } \\
\text { Financieros }\end{array}$ & $\begin{array}{l}\text { Opinión sobre informes de proyectos de } \\
\text { crédito evaluados* } \\
\text { Gestión de recursos financieros: fuentes y } \\
\text { aplicación de los recursos, disponibilidad } \\
\text { bancaria de fondos propios y provenientes } \\
\text { de convenios } \\
\text { Oportunidades de inversión en diferentes } \\
\text { instrumentos financieros* } \\
\text { Compromisos por créditos aprobados* } \\
\text { Resumen de vencimiento de cuentas por } \\
\text { cobrar } \\
\text { Informe de cobranzas* } \\
\text { Ejecución presupuestaria }\end{array}$ \\
\hline
\end{tabular}

Revisión de Informes para el Directorio

Administración de Programas y

Convenios

Administración y Recuperación

Gerencia General de Créditos

Administración de Personal

Desarrollo, Mantenimiento y

Protección de Planta y Equipo

Compras
Evaluaciones de proyectos, realizadas por los equipos correspondientes*

Nivel de ejecución de convenios y programas*

Situación de la cartera de crédito

Situación de efectivo e inversiones

Resultado de las operaciones realizadas por el FONDO

Compromisos de pagos a proveedores

" Información no incluida en informes Financieros habituales

Fuente: Leal, Miraidy et al. Intormación para Toma de Decisiones en Organismos Públicos de Financiamiento.

c. El Balance General y el Estado de Recursos y Egresos deberian presentarse en los dos meses siguientes al cierre del período económico, sin embargo, FONFIDEZ sólo los preparaba cuando la Contraloría los solicita para realizar la auditoría anual correspondiente. d. La situación de los recursos financieros del ente constituye una información sumamente importante, principalmente lo relacionado con disponibilidad de fondos, vencimiento de instrumentos financieros, intereses ganados por colocaciones. Sin embargo, ésta no es producida con la fre- 
Tabla No. 3

Características de los informes generados en FONFIDEZ

\begin{tabular}{|c|c|c|c|c|}
\hline \multirow[b]{2}{*}{ Informes } & \multirow[b]{2}{*}{ Destinatarios } & \multicolumn{2}{|c|}{ Variables } & \multirow[b]{2}{*}{ Pertinencia } \\
\hline & & Periodicidad & Oportunidad & \\
\hline $\begin{array}{l}\text { Balance } \\
\text { Ceneral }\end{array}$ & $\begin{array}{l}\text { Directorio } \\
\text { Contraloría Gene- } \\
\text { ral del Estado Zulia }\end{array}$ & $\begin{array}{l}\text { Debe sermensual, } \\
\text { sin embargo, se } \\
\text { elabora anualmen- } \\
\text { te }\end{array}$ & $\begin{array}{l}\text { Generalmente se } \\
\text { presenta con retra- } \\
\text { so }\end{array}$ & $\begin{array}{l}\text { No satisfacen las } \\
\text { necesidades de in- } \\
\text { formación a nivel } \\
\text { gerencial }\end{array}$ \\
\hline $\begin{array}{l}\text { Estado de } \\
\text { Recursos } \\
\text { y Egresos }\end{array}$ & $\begin{array}{l}\text { Directorio } \\
\text { Contraloria Gene- } \\
\text { ral del Estado Zulia }\end{array}$ & $\begin{array}{l}\text { Debe sermensual, } \\
\text { sin embargo, se } \\
\text { elabora anualmen- } \\
\text { te }\end{array}$ & $\begin{array}{l}\text { Generalmente se } \\
\text { presenta con retra- } \\
\text { so }\end{array}$ & $\begin{array}{l}\text { No satisfacen las } \\
\text { necesidades de in- } \\
\text { formación a nivel } \\
\text { gerencial }\end{array}$ \\
\hline $\begin{array}{l}\text { Situación } \\
\text { Bancaria }\end{array}$ & $\begin{array}{l}\text { Directorio } \\
\text { Presidencia } \\
\text { Gerencia General }\end{array}$ & $\begin{array}{l}\text { Debe ser diaria, } \\
\text { sin embargo, en la } \\
\text { institución no tiene } \\
\text { período especifi- } \\
\text { co. Se elabora } \\
\text { cuando lo requie- } \\
\text { ren los usuarios }\end{array}$ & $\begin{array}{l}\text { Se presenta en el } \\
\text { momento que } 10 \\
\text { solicitan }\end{array}$ & $\begin{array}{l}\text { Contiene cierta in- } \\
\text { formación necesa- } \\
\text { ria; sin embargo, la } \\
\text { estructura del in- } \\
\text { forme no es la más } \\
\text { adecuada }\end{array}$ \\
\hline $\begin{array}{l}\text { Situación } \\
\text { de la Cartera } \\
\text { de Crédito }\end{array}$ & $\begin{array}{l}\text { Directorio } \\
\text { Presidencia } \\
\text { Gerencia General }\end{array}$ & Mensual & $\begin{array}{l}10 \text { dias del mes } \\
\text { siguiente }\end{array}$ & $\begin{array}{l}\text { Presenta cierta in- } \\
\text { formación necesa- } \\
\text { ria para evaluar la } \\
\text { situación de los cré- } \\
\text { ditos, sin embargo, } \\
\text { es incompleta }\end{array}$ \\
\hline $\begin{array}{l}\text { Presupuesto } \\
\text { Anual }\end{array}$ & $\begin{array}{l}\text { Contraloria Gene- } \\
\text { ral del Estado Zulia } \\
\text { Directorio } \\
\text { Presidencia } \\
\text { Gerencia General }\end{array}$ & Anual & $\begin{array}{l}\text { Generalmente se } \\
\text { elabora en los me- } \\
\text { ses Agosto-Sep- } \\
\text { tiembre de cada } \\
\text { año }\end{array}$ & $\begin{array}{l}\text { Necesario para el } \\
\text { seguimiento perió- } \\
\text { dico de la ejecu- } \\
\text { ción presupuesta- } \\
\text { ria de pagos, inver- } \\
\text { siones y crédito } \\
\text { público }\end{array}$ \\
\hline $\begin{array}{l}\text { Informe de } \\
\text { Ejecución } \\
\text { Presupues- } \\
\text { taria }\end{array}$ & $\begin{array}{l}\text { Presidencia } \\
\text { Gerencia General }\end{array}$ & $\begin{array}{l}\text { Debe ser mensual, } \\
\text { sin embargo, en la } \\
\text { institución no se } \\
\text { emiten los Balan- } \\
\text { ces Generales y } \\
\text { los Estados de Re- } \\
\text { cursos y Egresos } \\
\text { mensuales, nece- } \\
\text { sarios para efec- } \\
\text { tuar la respectiva } \\
\text { comparación }\end{array}$ & $\begin{array}{l}\text { Debe presentarse } \\
\text { en los primeros } 10 \\
\text { dias del mes si- } \\
\text { guiente. Sin em- } \\
\text { bargo, enla institu- } \\
\text { ción no se emite } \\
\text { oportunamente }\end{array}$ & $\begin{array}{l}\text { Se requiere para } \\
\text { comparar los mon- } \\
\text { tos ejecutados con } \\
\text { los montos presu- } \\
\text { puestados; sin em- } \\
\text { bargo, la informa- } \\
\text { ción no es presen- } \\
\text { tada oportuna- } \\
\text { mente }\end{array}$ \\
\hline
\end{tabular}

Fuente: Leal, Miraidy el al. Información para Toma de Decisiones en Organismos Públicos de Financiamiento. 


\section{Características de los informes generados en FONFIDEZ}

\begin{tabular}{|c|c|c|c|c|}
\hline \multirow[b]{2}{*}{ Informes } & \multicolumn{4}{|c|}{ Variables } \\
\hline & Destinatarios & Periodicidad & Oportunidad & Pertinencia \\
\hline $\begin{array}{l}\text { Balance } \\
\text { General }\end{array}$ & $\begin{array}{l}\text { Directorio } \\
\text { Contraloría Gene- } \\
\text { ral del Estado Zulia }\end{array}$ & $\begin{array}{l}\text { Debe sermensual, } \\
\text { sin embargo, se } \\
\text { elabora anualmen- } \\
\text { te }\end{array}$ & $\begin{array}{l}\text { Generalmente se } \\
\text { presenta con retra- } \\
\text { so }\end{array}$ & $\begin{array}{l}\text { No satistacen las } \\
\text { necesidades de in- } \\
\text { formación a nivel } \\
\text { gerencial }\end{array}$ \\
\hline $\begin{array}{l}\text { Estado de } \\
\text { Recursos } \\
\text { y Egresos }\end{array}$ & $\begin{array}{l}\text { Directorio } \\
\text { Contraloría Gene- } \\
\text { ral del Estado Zulia }\end{array}$ & $\begin{array}{l}\text { Debe sermensual, } \\
\text { sin embargo, se } \\
\text { elabora anualmen- } \\
\text { te }\end{array}$ & $\begin{array}{l}\text { Generalmente se } \\
\text { presenta con retra- } \\
\text { so }\end{array}$ & $\begin{array}{l}\text { No satistacen las } \\
\text { necesidades de in- } \\
\text { formación a nivel } \\
\text { gerencial }\end{array}$ \\
\hline $\begin{array}{l}\text { Situación } \\
\text { Bancaria }\end{array}$ & $\begin{array}{l}\text { Directorio } \\
\text { Presidencia } \\
\text { Gerencia General }\end{array}$ & $\begin{array}{l}\text { Debe ser diaria, } \\
\text { sin embargo, en la } \\
\text { institución no tiene } \\
\text { periodo específi- } \\
\text { co. Se elabora } \\
\text { cuando lo requie- } \\
\text { ren los usuarios }\end{array}$ & $\begin{array}{l}\text { Se presenta en el } \\
\text { momento que lo } \\
\text { solicitan }\end{array}$ & $\begin{array}{l}\text { Contiene cierta in- } \\
\text { formación necesa- } \\
\text { ria; sin embargo, la } \\
\text { estructura del in- } \\
\text { torme no es la más } \\
\text { adecuada }\end{array}$ \\
\hline $\begin{array}{l}\text { Situación } \\
\text { de la Cartera } \\
\text { de Crédito }\end{array}$ & $\begin{array}{l}\text { Directorio } \\
\text { Presidencia } \\
\text { Gerencia General }\end{array}$ & Mensual & $\begin{array}{l}10 \text { dias del mes } \\
\text { siguiente }\end{array}$ & $\begin{array}{l}\text { Presenta cierta in- } \\
\text { formación necesa- } \\
\text { ria para evaluar la } \\
\text { situación de los cré- } \\
\text { ditos, sin embargo, } \\
\text { es incompleta }\end{array}$ \\
\hline $\begin{array}{l}\text { Presupuesto } \\
\text { Anual }\end{array}$ & $\begin{array}{l}\text { Contraloría Gene- } \\
\text { ral del Estado Zulia } \\
\text { Directorio } \\
\text { Presidencia } \\
\text { Gerencia General }\end{array}$ & Anual & $\begin{array}{l}\text { Generalmente se } \\
\text { elabora en los me- } \\
\text { ses Agosto-Sep- } \\
\text { tiembre de cada } \\
\text { año }\end{array}$ & $\begin{array}{l}\text { Necesario para el } \\
\text { seguimiento perió- } \\
\text { dico de la ejecu- } \\
\text { ción presupuesta- } \\
\text { ria de pagos, inver- } \\
\text { siones y crédito } \\
\text { público }\end{array}$ \\
\hline $\begin{array}{l}\text { Informe de } \\
\text { Ejecución } \\
\text { Presupues- } \\
\text { taria }\end{array}$ & $\begin{array}{l}\text { Presidencia } \\
\text { Gerencia General }\end{array}$ & $\begin{array}{l}\text { Debe ser mensual, } \\
\text { sin embargo, en la } \\
\text { institución no se } \\
\text { emiten los Balan- } \\
\text { ces Generales y } \\
\text { los Estados de Re- } \\
\text { cursos y Egresos } \\
\text { mensuales, nece- } \\
\text { sarios para efec- } \\
\text { tuar la respectiva } \\
\text { comparación }\end{array}$ & $\begin{array}{l}\text { Debe presentarse } \\
\text { en los primeros } 10 \\
\text { días del mes si- } \\
\text { guiente. Sin em- } \\
\text { bargo, enla institu- } \\
\text { ción no se emite } \\
\text { oportunamente }\end{array}$ & $\begin{array}{l}\text { Se requiere para } \\
\text { comparar los mon- } \\
\text { tos ejecutados con } \\
\text { los montos presu- } \\
\text { puestados; sin em- } \\
\text { bargo, la informa- } \\
\text { ción no es presen- } \\
\text { tada oportuna- } \\
\text { mente }\end{array}$ \\
\hline
\end{tabular}

Fuente: Leal, Miraidy et al. Información para Toma de Decisiones en Organismos Públicos de Financiamiento. 
cuencia requerida (diaria, semanal, quincenal), lo cual ha originado que en algunas ocasiones la Gerencia General no se haya percatado del vencimiento de algunas colocaciones bancarias.

Por otra parte, para determinar el uso que la Gerencia da a los informes recibidos se utilizó como base lo siguiente:

- Análisis de los informes generados por el sistema contable del organismo.

- Comparación entre las necesidades de información de los niveles decisorios (Directorio, Presidencia y Gerencia General) y la información suministrada por los informes correspondientes.

- Entrevistas al personal de FONFI. DEZ

Con base en el estudio realizado se llegó a la conclusión que FONFIDEZ se limita a emitir los estados contables para cumplir con los requisitos exigidos por la Contraloría General del Estado Zulia, pero en la institución dichos informes no son utilizados por el nivel gerencial, porque no satisfacen las características de periodicidad, oportunidad y pertinencia de la información. Para fundamentar la toma de decisiones el Fondo requiere, además de información en unidades monetarias "....información en unidades fisicas... en materia de gestión de recursos financieros, aprobación de créditos, gestión de cobranzas, seguimiento de proyectos financiados,..." (Gamboa et al, 1999).

Por otra parte, los informes contables (estados financieros) generados en la institución presentan las siguientes limitaciones para su uso:

a. Sólo presentan información cuantificable en términos monetarios. Exis- ten aspectos relevantes de la organización, de difícil valuación en unidades monetarias, que no se muestran en los Estados Financieros, tales como: experiencia, desempeño y motivación del personal; calidad del servicio; eficacia de las operaciones.

b. Uso de criterios inadecuados para la clasificación y registro de las transacciones y eventos económicos y su presentación en los informes. Sobre este aspecto es necesario destacar to siguiente: FONFIDEZ utiliza como referencia el Plan Único de Cuentas que debe emplearse en la formulación, ejecución y control del Presupuesto del Sector Público, el cual debe adecuarse a sus características y utilizar las cuentas que le sean propias. Sin embargo, se han presentado problemas en la clasificación de las partidas que componen los Estados Financieros porque el nombre de la cuenta, en algunas ocasiones, no se corresponde con la naturaleza de la partida registrada. Esto se ha originado, principalmente, por la poca capacidad técnica del personal encargado de operar y desarrollar el sistema de contabilidad, aunado al hecho que la supervisión y el control del registro de las operaciones (antes de la reestructuración), estaban a cargo de un profesional perteneciente a un área diferente a la Contaduría Públi$\mathrm{ca}$, lo que ha originado la baja calidad del trabajo realizado.

c. Los informes contienen información de carácter general sobre la entidad, intentan reflejar la situación de la organización como un todo pero no facilitan descubrir las causas reales de los problemas. 
d. Los informes responden básicamente a los requisitos propios de usuarios externos, aunque éste tipo de usuarios prácticamente no existe en la Institución, excepto la Contraloría General del Estado Zulia.

e. Generalmente se presentan con retraso porque el registro y procesamiento de las operaciones no se efectúa oportunamente.

En otros informes financieros elaborados, también se observan limitaciones debido a que no suministran información pertinente o, la forma de presentarla, no es la más adecuada.

Como se evidencia, el sistema contable en FONFIDEZ no funciona como sistema de información gerencial porque:

- No se produce la información en el momento preciso.

- Se elaboran informes sobrecargados de información innecesaria.

- La información útil se encuentra dispersa en varias fuentes, lo cual dificulta su ubicación.

- Los informes emitidos por diversas oficinas no siempre coinciden sobre el mismo asunto.

En consecuencia, para asegurar la generación de la información necesaria y pertinente, resultaba indispensable la reorganización del sistema de información, así como el rediseño de los informes, aprovechando las potencialidades de infraestructura y personal disponibles en la institución. Ésta contaba con un ingeniero en computación que se estaba prestando a medio tiempo a otro organismo porque all no tenía suficiente trabajo; además, casi todo el personal disponía de una computadora personal y manejaba los programas básicos de Window's. Todos los PC estaban conectados en red, pero no recibían uso institucional.

\section{Nuevas Tecnologías de Información, Reestructuración y Mercado Laboral para Contadores Públicos}

Castells (1999: 56) define la Tecnología de información (TI) como "el conjunto convergente de tecnologías de la microelectrónica, la informática (máquinas y software), las telecomunicaciones/televisión/radio y la optoelectrónica"..... Gerstein (1988: 5-6) coincide con Castells en cuanto a la inclusión del Hardware, el software y los otros dispositivos para la comunicación, así como en la presencia de la electrónica como característica de estos medios o recursos materiales para el manejo de la información.

El avance en la Tecnología de Información (TI) alteró en forma permanente y progresiva las economías del mundo, las organizaciones y la manera de trabajar. Según Edwards (1998: 2) desde los años sesenta, hasta principios de los ochenta, la atención se centraba en los sistemas de información que necesitaban las empresas, la tecnología se obtenía y aplicaba para satisfacer estas demandas; hoy, la atención se ha volcado hacia aplicaciones más innovadoras y fructíferas de la tecnología, es decir, hacia la oferta.

En tal sentido, toda organización debe contar con una estrategia de $\mathrm{Tl}$, lo cual "supone determinar la forma en que han de desarrollarse las aplicaciones, y cómo se van a adquirir, utilizar, controlar y gestionar los recursos tecnológicos y humanos necesarios para satisfacer las 
necesidades de la empresa" (Edwards, 1998: 34).

La adopción de una nueva tecnología conlleva siempre un riesgo, pero también una oportunidad, por eso, no sólo es importante saber que nuevas tecnologías se están desarrollando y, cómo las están utilizando los demás, sino también, poder reconocer las oportunidades de negocios latentes en la tecnología que se dirijan al logro de una ventaja competitiva (Edwards, 1998:36-37; Hammer y Champy, 1996:93).

Al respecto, Hammer y Champy (1996: 95) expresan, "el poder real de la tecnología no está en que pueda hacer funcionar mejor los viejos procesos, sino, en que le permita a las organizaciones romper las reglas y crear nuevas maneras de trabajar, es decir, rediseñar."

Según Robbins (1998: 225), la importancia de la tecnología es su capacidad de incrementar la productividad, entendiéndola como la relación entre la cantidad de bienes o servicios que se producen o brindan y los recursos materiales, económicos y humanos necesarios para producirlos o brindarlos. Este es uno de los principales objetivos de una organización y para lograrlo muchas veces rediseñan los trabajos, proceso en el cual tiene gran importancia la $\mathrm{Tl}$ a emplear.

Un elemento clave en las nuevas tecnologías de información es la automatización, que generalmente está contemplada en los procesos de rediseño que emprenden las compañías; pero automatizar los mismos procesos existentes utilizando nuevos hardware y soltware no significa la solución de los problemas; lo importante es usar "bien" la $\mathrm{TI}$, no simplemente para dar soluciones a los problemas, sino que, al descubrir una aplicación útil y novedosa de la $\mathrm{TI}$, se busque el aspecto a transformar, los problemas que ella podría resolver y que tal vez la compañía ni se ha percatado de ellos. Actuar de esta manera corresponde a pensar de forma inductiva (soluciones - problemas a resolver) y no simplemente de forma deductiva (problemas por resolver - soluciones), que es la más común en el pensamiento de los gerentes, según lo afirman Hammer y Champy (1996: 89-90). Este pensamiento inductivo acelera el cambio tecnológico y promueve la innovación.

Al igual que las nuevas $\mathrm{TI}$, los procesos administrativos se modifican a pasos agigantados, de modo que el gerente, administrador, ejecutivo de hoy debe tener conocimiento de estas nuevas $\mathrm{TI}$ para que la modernización de los sistemas de información y los diseños de trabajo sean exitosos.

Al respecto, Laudon (1996: 17) expresa que las primeras TI y Sistemas de Información simplemente automatizaban procesos esencialmente operativos que los gerentes podian delegar; pero posteriormente éstos han venido afectando directamente la toma de decisiones de los administradores, la planificación gerencial, incluso qué productos y servicios se producen y ofrecen. Por lo tanto, los gerentes de hoy no pueden simplemente delegar y desligarse de estos Sistemas de Información y Tl; existen incluso sistemas diseñados especialmente para ayudar a los gerentes en sus funciones; algunos ejemplos son: Sistemas de Soporte de Decisiones -SSD- (Laudon, 1996: 606), Sistemas de Soporte de Decisiones de Grupo -SSDG- (Laudon, 1996: 617), 
Sistema de Soporte a Ejecutivos -SSE(Laudon, 1996: 626), Balanced Score Card o Cuadro de Mando Integral (Kaplan y Norton, 2000), Administración en una Página (Khadem y Lorber, 1995).

La TJ avanza aceleradamente, sobre todo en lo referente a la informática, tanto en el hardware como en el software, a través del uso de multimedia, de los súper chips y del cambio en la forma de procesar la información. Multimedia son "las tecnologías que facilitan la integración de dos o más tipos de medios, como textos, gráficas, sonido, voz, video de movimiento total, video fijo o animación en una aplicación basada en la computadora"; y los super chips son "el resultado de las investigaciones en semiconductores que han hallado medios para comprimir los circuitos más densamente, de manera que millones de transistores puedan ser empacados en una oblea de silicón del tamaño de una uña." Esto ha permitido reducir el tamaño de las computadoras, al tiempo que aumenta su capacidad y velocidad de respuesta. Se puede decir que hoy podemos tener el poder de una macro computadora y aún de una supercomputadora, (que ocupaban enormes espacios físicos) sobre un escritorio e incluso llevarla de un lugar a otro en forma de maletín o como calculadora de bolsillo (Laudon, 1996: 210-213).

Asimismo, el procesamiento de la información ha evolucionado, ya no tiene que ser instrucción por instrucción, es decir, en serie, sino que se pueden procesar en paralelo y masivamente en paralelo para "mezclar voz, imágenes y altos volúmenes de datos de diversas fuentes, usando inteligencia artificial y modelos matemáticos de extrema complejidad". Estos avances han provocado cambios profundos en la manera de trabajar, pues no solo han permitido la automatización de los procesos, la cual proporciona mayor velocidad y precisión, sino que han facilitado la innovación y el cambio.

Es de resaltar que la relación entre el avance tecnológico y su costo es inversamente proporcional. De mantenerse en el futuro, avances tecnológicos, como la Internet podrán ser cada vez más del dominio público (popular), como lo son el teléfono o la televisión, que aún en hogares muy modestos están presentes.

Los cambios tecnológicos no han sucedido aislados, por el contrario, aunados a ellos y en interacción se han dado una serie de cambios políticos, económicos, laborales, culturales y gerenciales que influyen en las organizaciones. Existe una influencia reciproca entre la TI y las organizaciones. Las organizaciones deciden la nueva $\mathrm{Tl}$ a adquirir e implementar y ésta al mismo tiempo incide en su desempeño e incluso conlleva a la reestructuración o a la reingenieria. En el caso del organismo de financiamiento analizado, a pesar que contaba con una dotación de computadores en una relación con el volumen de personal cercana a $1 / 1$, los mismos recibian un uso muy limitado, casi el equivalente a máquinas de escribir.

En consecuencia, la reestructuración centró la atención en el uso de algunas aplicaciones genéricas existentes y en el diseño de software adecuado a las necesidades de la organización, para optimar los procesos básicos y los de apoyo.

Entre los enfoques administrativos (subcontratación, alianzas estratégicas, reingeniería, reestructuración, entre otros), que han surgido vinculados al desarrollo tecnológico para que las organiza- 
ciones estén en capacidad de enfrentar las restricciones financieras y responder a las exigencias de un entorno cada vez más competitivo y globalizado, en el ente analizado, el equipo de consultoría y la presidencia optaron por la reestructuración, pero partiendo del enfoque de reingeniería sin llegar a los extremos radicales de empezar de cero y, tratando de aprovechar al máximo el potencial disponible en el personal, así como facilitando su capacitación y la integración de los grupos de trabajo; sin embargo, la tendencia en los procesos de reestructuración o reingeniería, es la reducción de personal, especialmente en los niveles gerenciales.

La reestructuración y la reingeniería producen tanto efectos negativos como positivos dependiendo del punto de vista desde el cual se observe. Aquello que genera ventajas para la organización, en cuanto facilita la reducción de costos, afecta las posibilidades laborales del personal.

Aunque, según Hammer y Champy (1996: 50), el proceso de reestructuración y el de reingeniería son diferentes, las consecuencias de su aplicación son similares. La principal y que más revuelo en posiciones encontradas ha tenido es la reducción de puestos de trabajo, tanto en el nivel operativo como en los niveles medios de la estructura organizacional.

Según Rifkin (1996: 18, 23) "tan sólo en el mes de enero de 1994 los empresarios americanos más importantes dejaron sin trabajo a más de 108.000 trabajadores", y cada año, en los Estados Unidos, se eliminan más de dos millones de puestos de trabajo.
Hammery Champy (1996: 151) establecen como uno de los principios fundamentales de la reingeniería, que los procesos deben incluir el menor número de personas posibles, y están conscientes de los efectos negativos que se desprenderán de ello.

Bjur (1996: 12-13) afirma que la reingeniería crea un ambiente de miedo; además, Andrade y Campo Redondo (1998: 253), refieren varios estudios donde muestran que los empleados que consevan un lugar en la organización sometida a procesos como la reingeniería $u$ otros, tendientes a la reducción de empleos, muchas veces se desaniman, se retraen y se vuelven adversos al riesgo, disminuyen su productividad y sienten amenazada su estabilidad laboral, lo que contradice la idea de Hammer y Champy que la reingeniería hace el trabajo más satisfactorio y productivo.

El avance tecnológico siempre ha provocado la reducción de empleos en un área y la creación de empleos en otra pero, según las investigaciones realizadas por Rifkin (1996: 13-17) más de 800 millones de seres humanos están en la actualidad desempleados o subempleados en el mundo. La oferta de nuevos empleos a raíz de los avances en la tecnología son inferiores a la desaparición de empleos que provoca.

Los efectos de la TI y de los cambios en la forma de organización y producción de las empresas han sido tan notables, que han dividido la historia del trabajo en etapas con diferencias bien marcadas. Robbins (1998: 7) sustentándose en Alvin Toffler, divide el crecimiento y declive de los sectores de trabajo en tres "olas". La primera ola fue la agricultura; hasta finales 
del siglo XIX, alrededor del $90 \%$ de la población trabajaba en esta área. La segunda ola fue la industrialización, cuya producción se basaba en máquinas, de finales del siglo XIX a la década de los 60 , donde se dio la migración del campo a las ciudades $y$, la tercera ola iniciada en los 70 se fundamenta en la información, basada en los avances tecnológicos de las telecomunicaciones y la electrónica.

Realmente estamos en la era de la información. Las nuevas TI basadas en la electrónica están conduciendo a la reducción del trabajo, tanto en el sector agrícola, como en el de manufactura y el de servicios. Se proyecta para mediados del siglo XXI una economía basada casi exclusivamente en la automatización. Al parecer el único sector que ofrece nuevas oportunidades para el ser humano es el del conocimiento, conformado alrededor de la $\mathrm{TI}$, pero a pesar de su auge no se puede esperar que emplee más que a una pequeña parte del gran número de desempleados que provocarán los mismos avances en las comunicaciones y la información. Las nuevas $\mathrm{TI}$ y las de telecomunicaciones, tienen la capacidad de mejorar o empeorar la situación laboral en el mundo en este siglo que comienza. Podrían darle a los empleados mayor disposición de tiempo libre y un trabajo más fácil y ameno o simplemente provocar un desempleo masivo y una depresión global (Rifkin, 1996: 17-20).

En la época de la revolución industrial, era la fuerza corporal del hombre la que se sustituia por las máquinas, pero en la era de la información y del conocimiento se busca sustituir la propia mente humana por tecnologías basadas en la electrónica. Esto traería consigo una so- ciedad masivamente desempleada, donde los empleos intermedios son los más afectados por los procesos de reestructuración y reingeniería; las empresas han eliminado las posiciones administrativas medias y han aplanado sus estructuras para reducir costos. (Rifkin, 1996: 25,27; Robbins, 1998: 19, 42-43).

La experiencia demuestra que la actuación del contador para apoyar la función gerencial se reduciría en aquellas organizaciones sometidas a la reingeniería. Al aplicar ésta, los procesos se comprimen horizontal y verticalmente, afectando las funciones de comprobación, registro y control de trabajo que tradicionalmente han desempeñado contadores, auditores y supervisores en organizaciones con estructuras administrativas jerárquicas (Hammer y Champy, 1996: 56). Por otra parte, los desarrollos en informática agilizan el procesamiento de información. Según extractos de noticias señaladas por Robbins (1998: 43, 144, 176), la automatización, el compartimiento de información y la facultación de empleados han ido eliminando la necesidad de contar con gerentes que supervisen el trabajo cotidiano. Los empresarios ya no quieren, ni pueden sostener, más ejércitos de gerentes de nivel medio para que compilen la información, contesten preguntas y pasen instrucciones de arriba hacia abajo en la escalera corporativa. Además, no los necesitan. La tecnologia puede hacer el trabajo por ellos. No sólo están cambiando las organizaciones y los trabajos de los empleados, sino también el trabajo gerencial, ya que éstos tienen que adaptarse al cambio y al mismo tiempo ser propiciadores del cambio. 
Es evidente que todo lo anterior significa un riesgo en el mercado laboral para los profesionales de la Contaduría Pública, que posiblemente exige ampliar el campo de acción profesional y estar preparado para captar, interpretar y enfrentar los desafíos crecientes propios de su desempeño y los constantes cambios de nuestra sociedad. Específicamente en Venezuela, una investigación realizada sobre la situación laboral de los egresados en Administración y Contaduria Pública del Núcleo de Punto Fijo de la Universidad del Zulia durante el período 1991-1998 señala que aproximadamente un $33 \%$ están desempleados o subempleados. El estudio realizado sugiere que para mejorar la crisis del desempleo es necesario reformular la formación profesional, brindando no sólo entrenamiento sino educación, para formar profesionales polivalentes capaces de satisfacer los requerimientos de empleo (Narváez, 2000: 416-417, 420).

Durante mucho tiempo, la presencia del Contador Público en una institución privada o pública ha obedecido primordialmente a la necesidad de rendir información sobre la situación financiera y económica de la misma a entes externos, tales como, el Fisco Nacional, contralorías regionales $u$ otros órganos reguladores, asi como a instituciones financieras o inversionistas potenciales, con el fin de cumplir con obligaciones legales y evitar sanciones $u$ obtener nuevos recursos financieros, respectivamente; pero no se ha explotado, ni aprovechado suficientemente el gran potencial contable para suministrar a la gerencia la información útil, suficiente y oportuna que le permita controlar, evaluar y tomar decisiones adecuadas en cuanto a las operaciones habituales de la empresa y a sus metas y proyectos.

Es esta última área de competencia de la contabilidad, en donde se hace énfasis en las necesidades internas de información de la organización, la cual es denominada "Contabilidad Administrativa", según la Declaración de Principios de Contabilidad $N^{\circ} 0$ (DPC 0 ) emitida por la Federación de Colegio de Contadores Públicos de Venezuela, donde el profesional de la Contaduría Pública debe profundizar y afinar sus conocimientos y habilidades para abrirse campo en el mercado laboral al hacer notar la utilidad de los servicios de un contador para el buen funcionamiento de la organización, ya que la otra área, la denominada "Contabilidad Financiera", ha sido suficientemente abordada por los contadores hasta el momento, y no brinda la información necesaria para la gestión administrativa diaria.

La base fundamental para que el contador logre posicionarse en el mercado laboral es que brinde información, tanto financiera como no financiera, realmente útil, clara y concisa para la toma de decisiones. Esto se puede lograr a través de la elaboración de informes cortos que proporcionen una visión global del contexto para cada nivel gerencial, sin saturar con datos innecesarios y que permitan concatenar lo que se hace con las metas previstas.

\section{Conclusiones}

Un adecuado sistema contable debe ser capaz de suministrar información útil para la toma de decisiones oportunas a los diferentes usuarios de la misma. Sin embargo, dicho sistema en el organismo objeto de estudio pre- 
Información para la toma de Decisión

Leal M., Miraidy; Gamboa C., Teresa y Briceño Q., Maria

senta deficiencias en este sentido, ya que se limita a producir estados contables sólo para cumplir con requisitos exigidos por la Contraloría General del Estado Zulia; en la institución dichos informes no son utilizados por la dirección porque no satisfacen las necesidades diarias de información gerencial. La mayoría de ellos no satisfacen las características de periodicidad, oportunidad y pertinencia de la información, evidenciándose poca correspondencia entre la información suministrada por dichos informes y las necesidades de información de los niveles decisorios.

En la práctica contable se ha dado mayor importancia a la contabilidad financiera, concentrándose en la preparación de informes para usuarios externos, restándole importancia a la preparación de informes para uso interno; los Contadores Públicos generalmente se han dedicado a manejar y suministrar información financiera dejando de considerar la no financiera, por lo cual los informes contables en muchas ocasiones no son utilizados por la gerencia para el proceso administrativo continuo. Si bien la contabilidad ha existido desde épocas muy remotas, la década presente y los tiempos futuros le asignan grandes responsabilidades en la conducción de las organizaciones hacia el logro de sus objetivos; es por ello que el profesional de la Contaduría Pública debe estar en un proceso continuo de investigación y actualización profesional y de revisión de los esquemas contables, para adecuarlos a la realidad y a las exigencias de las organizaciones.

Las nuevas tecnologías de información proporcionan las bases para la sus- tentación de los sistemas de información $y$ las nuevas estructuras organizacionales que conducen, con frecuencia, a cambios en las relaciones laborales y a la reducción del empleo, a través de la aplicación de mecanismos administrativos como la reestructuración y la reingeniería.

Por lo tanto, el desarrollo tecnológico en informática y las tendencias del mercado laboral plantean retos a la Contaduría Pública, que deben ser asumidos para evidenciar la utilidad de los servicios profesionales y garantizar fuentes de trabajo.

\section{Bibliografía citada}

Andrade, Jesús y Campo-Redondo, María (1998). Tecnologías de Información en el Diseño de la Organización. Revista Venezolana de Gerencia, Año 3, $N^{\circ} 6$, Venezuela, La Universidad del Zulia, Vicerrectorado Académico, pp 241-256.

Asamblea Legislativa del Estado Zulia - ALEZ (1994). Ley para la Creación del Fondo Rotatorio para el Financiamiento y Desarrollo de la Artesanía, Pequeña y Mediana Industria del Estado Zulia. Venezuela.

Bernstein, Leopold (1996). Análisis de Estados Financieros. Teoría, Aplicación e Interpretación, España, Times Mirror de España.

Bjur, Wesley (1996). De la Reingeniería a la Readministración. En busca de nuevo paradigma. Revista Venezolana de Gerencia. Vol. I, $N^{\circ} 1$, Venezuela, La Universidad del Zulia, Vicerrectorado Académico, pp. 3-25.

Castells, Manuel (1999). La Era de la Información. Economia, Sociedad y Cultura, La Sociedad Red. Vol. I, México, Siglo Veintiuno Editores, S.A. 
Cubillán, Raiza (1998). Sistemas de Costos de Hospitalización en Clínicas Privadas. Revista Venezolana de Gerencia, Año $3, N^{\circ} 5$, Venezuela, La Universidad del Zulia, Vicerrectorado Académico, pp 111-129.

Edwards, Chris; Ward, John y Bytheway, Andy (1998). Fundamentos de Sistemas de Información. 2da. Edición, España, Prentice May.

Federación de Colegio de Contadores Públicos de Venezuela (1997). Declaración de Principios de Contabilidad $N^{\circ} \mathrm{O}$ “Normas Básicas y Principios de Contabilidad de Aceptación General". Venezuela.

Gamboa, Teresa et al (1999). Informe de Evaluación del Fondo Rotatorio para el Financiamiento y Desarrollo de la Artesania, Pequeña y Mediana Industria del Estado Zulia (FONFIDEZ). Venezuela.

Gerstein, Marc S. (1988). Encuentro con la Tecnología. Estrategias y Cambios en la Era de la Información, México, Addison-Wesley Iberoamericana.

Guajardo, Gerardo (1995). Contabilidad Financiera. 2da. Edición. México, Mc. Graw Hill Interamericana.

Hammer, Michael y Champy, James (1996). Reingeniería. Ona. Reimpresión. CoIombia. Grupo Editorial Norma.

Kaplan, Robert S. y Norton, David (2000). EI Cuadro de Mando Integral (The Balance Score Card), España. Ediciones Gestión 2000, S.A.

Khadem, Riaz y Lorber, Robert (1995). Administración en Una Página. Cómo utilizar la información para lograr sus metas. 12da. Reimpresión. Colombia. Grupo Editorial Norma.

Laudon, Kenneth C. y Laudon, Jane P. (1996). Administración de los Sistemas de Información. Organización y Tecnología. 3ra. Edición, México, Prentice May Hispanoamericana, S.A.

Name Aguilar, Alberto (1980). Contabilidad General I. Cuba, Editorial Pueblo y Educación.

Narváez, Mercy y otros (2000). Situación Laboral de Administradores y Contadores egresados de la Universidad del Zulia. Revista Venezolana de Gerencia, Año $5, N^{\circ} 12$, Venezuela, La Universidad del Zulia, Vicerrectorado Académico, pp. 413-427.

Osborne, David y Gaebler, Ted. (1994). La Reinvención del Gobierno. La influencia del espiritu empresarial en el sector público. España, Ediciones Paidós Ibérica, S.A.

Redondo, Angel (1992). Curso Práctico de Contabilidad General y Superior. Tomo I. Venezuela, Centro Contable Venezolano.

Rifkin, Jeremy (1996). El Fin del Trabajo. Nuevas Tecnologías contra Puestos de Trabajo: El Nacimiento de una Nueva Era. España, Editorial Paidós.

Robbins, Stephen P. (1998). La Administración en el Mundo de Hoy. México, Prentice May Hispanoamericana, S.A.

Rodriguez, Guillermo (1999). Gerencia Estratégica sustentada por el Costeo basado en Actividades. Revista Venezolana de Gerencia. Año $4, N^{\circ} 7$, Venezuela, La Universidad del Zulia, Vicerrectorado Académico, pp. 21-35. 